\begin{tabular}{|c|c|}
\hline $\begin{array}{l}\text { Teorías de la disidencia sexual: de contextos populares a usos elitistas. La teoría } \\
\text { queer en América latina frente a las y los pensadores de disidencia sexogenérica }\end{array}$ & Titulo \\
\hline González Ortuño, Gabriela - Autor/a; & Autor(es) \\
\hline $\begin{array}{l}\text { De Raíz Diversa. Revista Especializada en Estudios Latinoamericanos (Vol. } 3 \text { no. } 5 \\
\text { ene-jun 2016) }\end{array}$ & En: \\
\hline México D.F. & Lugar \\
\hline $\begin{array}{l}\text { Programa de Posgrado en Estudios Latinoamericanos, Universidad Nacional } \\
\text { Autónoma de México }\end{array}$ & Editorial/Editor \\
\hline \multirow[t]{2}{*}{2016} & Fecha \\
\hline & Colección \\
\hline $\begin{array}{l}\text { GLTB'S (Colectivo vinculado a gays/lesbianas/trans/bisexuales); Diversidad sexual; } \\
\text { Sexualidad; Pensamiento latinoamericano; Literatura latinoamericana; América } \\
\text { Latina; }\end{array}$ & Temas \\
\hline Artículo & Tipo de documento \\
\hline $\begin{array}{l}\text { "http://biblioteca.clacso.edu.ar/Mexico/ppel-unam/20160630033827/8._Teorias_de_la_disidencia_sexual._-Gabriela_Gonzalez_Ortuno.pd } \\
\text { f" }\end{array}$ & URL \\
\hline $\begin{array}{l}\text { Reconocimiento-No Comercial-Sin Derivadas CC BY-NC-ND } \\
\text { http://creativecommons.org/licenses/by-nc-nd/2.0/deed.es }\end{array}$ & Licencia \\
\hline
\end{tabular}

Segui buscando en la Red de Bibliotecas Virtuales de CLACSO http://biblioteca.clacso.edu.ar

Consejo Latinoamericano de Ciencias Sociales (CLACSO)

Conselho Latino-americano de Ciências Sociais (CLACSO)

Latin American Council of Social Sciences (CLACSO)

www.clacso.edu.ar
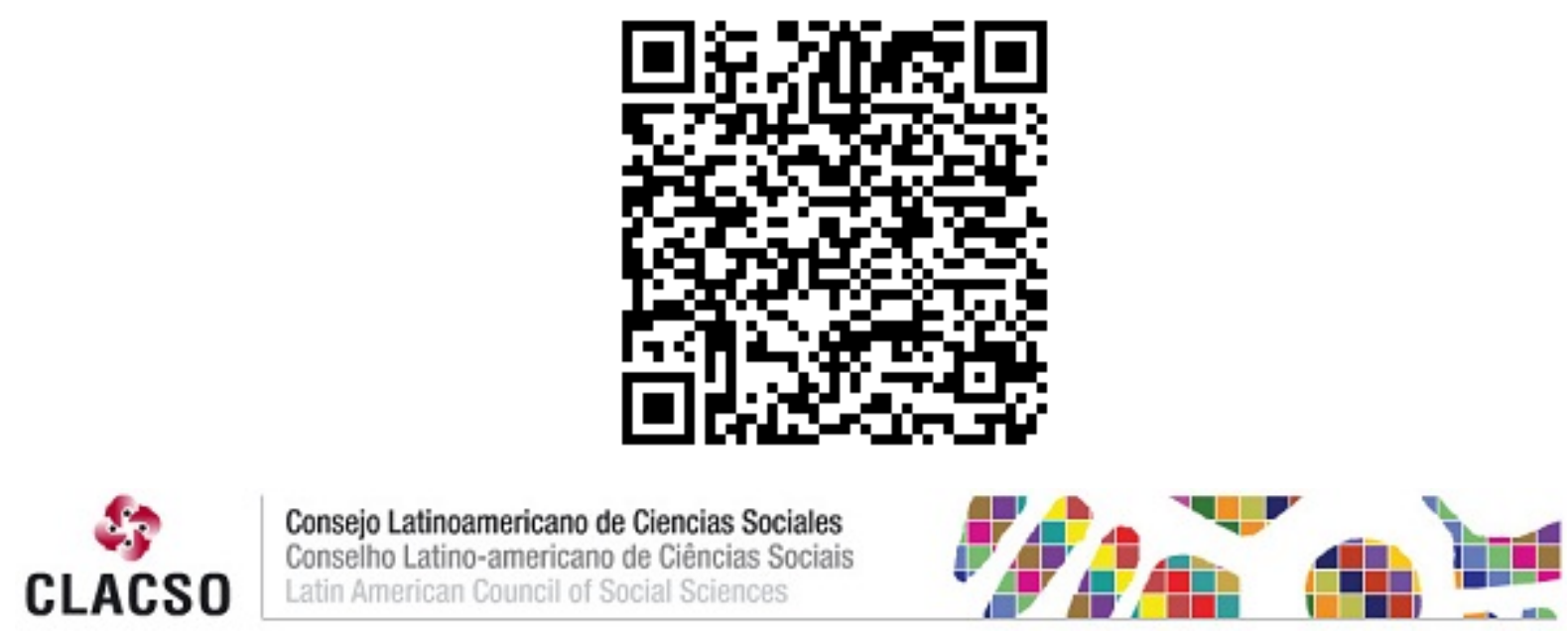


\title{
Teorías de la disidencia sexual: de contextos populares a usos elitistas. La teoría queer en América latina frente a las y los pensadores de disidencia sexogenérica
}

\author{
Gabriela González Ortuño*
}

RESUMEN: Este artículo pretende poner a debate el uso de la teoría queer como herramienta teórica para pensar las disidencias sexogenéricas frente a una serie de autoras y autores latinoamericanos que han reflexionado acerca de dicha disidencia, desde su interseccionalidad con raza, clase y espacios geográficos. Estas autoras y autores han desarrollado un corpus literario y una producción teórico social que reflejan, no sólo posiciones, sino estrategias para resistir y construir relaciones distintas entre sectores sociales. Sería posible hablar, de tal forma, de una teoría de la disidencia sexual latinoamericana surgida desde contextos populares frente a los usos elitistas que se dio a la teoría queer en América latina.

Palabras clave: Teoría queer, disidencia sexual, feminismos, literatura latinoamericana.

Abstract: This article aims to discuss the use of queer theory as a theoretical tool to think sex and gender dissent against a number of Latin American authors who have thought about this and intersectionality of race, class and geographical areas. These authors have developed a literary corpus and theoretical social production that reflects not only the position, but strategies to resist and build relationships between different social sectors. It would be possible to speak, so, from a Latin American theory of sexual dissidence emerged from popular contexts against the elite uses that gave the queer theory in the continent.

KEYWORDS: queer theory, sexual dissidence, feminism, Latin American literature.

Recibido: 01 de agosto de 2015. ACEPTAdo: 09 de septiembre de 2015.

Doctoranda del Programa de Posgrado en Estudios Latinoamericanos, <gaby.ggo@ gmail.com>. 
Yo te aguardé esta noche con el ansia de mirarte llegar, $y$ de que luego escucharas impávido mi ruego $y$ me dieras tu fuerza y tu fragancia. Pero quisiste darte la elegancia de no venir, de desdeñar mi fuego, sin saber que recibo por entrego leche de muchos toros en mi estancia.

Yo pensaba quererte en exclusiva; gemir y sollozar bajo tu fuete, brindarte mis pasiones rediviva. Y a casa regresé - con tu billeteluego que una salubre lavativa a los hijos ahogó de otro cadete.

Salvador Novo

$\mathrm{L}$ as comunidades homosexuales, bisexuales y transexuales en América latina han encontrado un sinnúmero de dispositivos de contención a su sexualidad y su degenaración, ${ }^{1}$ desplegados a través de múltiples instituciones: escuelas, iglesias, juzgados. La estigmatización y exclusión de los disidentes sexuales aparece en todo el mundo, aunque las formas de representación y resistencia son localizadas culturalmente. Incluso en el caso de los muxes zapotecos, ejemplo típico de una supuesta convivencia pacífica y aceptación de la homosexualidad en una comunidad tradicional, éstos han sido interpelados por comenzar a vestir como mujer y no, como tradicionalmente lo hacían, como hombres.

A partir de la condena a sus formas de relacionarse sexualmente con otras personas o de degenerarse, los disidentes sexuales latinoamericanos han constituido identidades políticas desde la resistencia a dichos dispositivos, las comunidades disidentes sexuales y de género han también, multiplicado sus formas de lucha. De tal forma que el apelativo homosexual o su equi-

1 Con degenerados o degeneradas haremos referencia a las personas cuya disidencia se centra en la desmarcación de las pautas de género tradicionales. Ejemplos de esto son Beatriz Preciado o las personas transexuales o travestidas, sobre todo las llamadas locas fuertes cuya característica es que a pesar de ser biológicamente varón han decidido mostrar su preferencia por vestirse de mujer sin renunciar a algunas características consideradas masculinas como el tono de voz o el vello corporal. 
valente inglés $g a y^{2}$ se consideró insuficiente para hablar de una población diversa que tampoco se sentía parte de un estilo de vida de homosexualidad normalizada que entraba dentro de algunos estándares de consumo y de organización social y de género muy determinados. Por otro lado, las organizaciones de lesbianas, gays, transexuales, bisexuales e intersexuales (LGTBI) que parecieran más abiertas a la diversidad también han sido criticadas al ser consideradas organizaciones de clase media y alta, racistas, con una visión occidental de las diferentes posturas de género y sexuales, y que comercializan la lucha de los disidentes sexuales y genéricos empobrecidos y racializados a través de posturas festivas, que dejan de lado reivindicaciones políticas de las diversas formas de disidencia sexogenérica.

El objetivo de este artículo es analizar las posturas de este sector crítico que desde la disidencia sexual ${ }^{3} \mathrm{y}$ de género en América latina ha abierto un frente de lucha social y reflexión en torno a las corrientes hegemónicas de pensamiento. Estas posturas tienen un respaldo histórico en los diversos frentes de actuar y de lucha en la región que, aunque puede presentar algunas similitudes con su contraparte europea, no presentan los mismos contenidos, sobre todo en relación a contenidos raciales y de espacios, así como la forma en la que se imbrican las condiciones políticas y económicas del continente que aún lucha contra su legado colonial.

La disidencia sexual ha encontrado en las últimas décadas a la teoría queer como su corriente hegemónica de pensamiento, sin embargo, a pesar de tratarse de un pensamiento subversivo, los espacios de reflexión en torno al tema en América Latina han llevado a cabo una fuerte crítica a dicha teoría, sobre todo porque la misma ha sido utilizada por formas de ser homosexual desde lugares de privilegio en las sociedades no occidentales.

2 Sergio Tellez Pon (2014) en su breve artículo "Por una literatura queer" analiza el origen de la palabra gay que sitúa más cerca de lenguas romance que de vocablos ingleses, aunque finalmente reconoce que dicho vocablo conlleva un estilo de vida normalizado.

3 Usaremos disidencia desde la acepción de disidir, no de disentir. Disentir es una acepción relativa a no ajustarse al sentir o parecer de alguien, mientras disidir según la Real Academia de la Lengua es separarse de la común doctrina, creencia o conducta. Esto implica que no se trata de un simple desacuerdo sino de la intención de tomar distancia de lo establecido para buscar construir relaciones diversas. Se ha preferido utilizar el término disidencia sexual sobre el de homosexualidad para dar cuenta de un espectro más amplio de preferencias o conductas sexuales respecto a la heterosexualidad normativa. De la misma forma, nos parece que es una forma de no invisibilizar a la homosexulidad femenina o lesbianismo, ya que la palabra homosexual en muchas ocasiones hace referencia únicamente a la homosexualidad masculina. 
En América Latina, lo queer ha pasado por un examen crítico en diversos círculos de pensamiento: desde las lesbianas negras hasta los movimientos de sexualidad diversa de diferentes corrientes que toman a la teoría como una forma de imponer teorías blancas occidentales al resto del mundo.

El uso del término queer es atractivo para los movimientos de disidencia sexual, por lo que se han buscado traducciones al término como torcido o excéntrico; también se ha buscado latinizar el término para dar cuenta de una forma de disidencia sexual desde este continente, de tal forma que cuir es utilizado entre diversos movimientos de disidentes sexuales y de género, que en su mayoría se asocian a alguna forma de expresión artística, sobre todo, el performance, y a algunos círculos académicos de la región. ${ }^{4}$ El debate del uso queer como práctica política, el surgimiento de la teoría queer y de su reapropiación (cuir, torcido, excéntrico) y las críticas que consideran una extensión de la visión patriarcal y colonial nos lleva a recorrer las diversas formas de expresión de la disidencia sexual desde el mundo no europeo.

Para comenzar, queer es un término reapropiado por los disidentes sexuales ingleses, quienes frente a la burla y la humillación por ser llamados de esa forma, lo asumen y reapropian la locución como su vocablo de identificación. Éste término se retoma políticamente para hacer una crítica a la homosexualidad normalizada, es decir, a los sectores homosexuales que adoptan roles generonormativos (hombre/mujer) y se adaptan a las condiciones laborales y visión de éxito y desarrollo del sistema moderno liberal capitalista. Lo único que buscan es ser incluidos en el orden, no transfromarlo. El término queer también fue usado para referir al tipo de disidencia sexual y de género que se acerca al travestismo de los sectores empobrecidos, por lo que se trataba de una forma de escarnio. Una vez surgido el movimiento político que se reapropiaba el término para hacerse valer como sujetos de derechos, este término se trasladó a la academia. Teresa de Lauretis comenzó a utilizar el término de teoría queer para hablar de una forma de disidencia sexual y género en busca de cruzar lo sexual con otras categorías como raza, sin embargo, es un proyecto que más tarde abandonará (Mogrovejo, 2010). La teoría queer nace como subversión de

4 Por ejemplo, Sayak Valencia en su artículo “Tijuana Cuir” o "Diego Falconi” que habla del impacto de la teoría cuir/cuy(r)/queer en la literatura latinoamericana, sin embargo, este artículo defiende que no es necesario hacer uso de dichos conceptos que sólo hacen un intento de apropiación de una teoría que hace referencia a una propuesta de pensamiento que se desarrolla desde hace cerca de medio siglo en América latina. 
las grandes teorías para pensar géneros y sexualidades pero deja su lugar de teoría marginal rápidamente y se populariza en todo el mundo a partir de su desarrollo en los países sedes de la producción de conocimiento hegemónico.

Las primeras críticas a dicha teoría vienen de su propia forjadora, Teresa de Lauretis, quien refiere un uso indiscriminado del término por parte de los movimientos LGTBI que priorizan al género sobre la sexualidad, aunque la principal razón para abandonar la teoría queer que la autora esgrime es que ésta se había tornado algo "comercial y vacío". ${ }^{5}$ De ahí, múltiples voces, sobre todo iberoamericanas, han debatido acerca de la pertinencia del uso de la teoría queer. Para Rivas (Rivas SanMartín, 2011), lo queer debe pensarse como contextual y político, por lo que se debe respetar la importancia fonética angloparlante ya que "La indeterminación gramatical de "lo queer" en castellano, determina la imposibilidad de referirse a un particular específico" que a la vez, interpela desde la exterioridad del castellano, ${ }^{6}$ lo que nos colocaría frente a una aparente superword, que atiende a cierta inteligibilidad que "logra señalar todo lo que no se ajusta a las normas" (Rivas SanMartín, 2011) a partir de la desestabilización de identidades. La indeterminación gramatical e identitaria es el postulado a partir del que aparecen desarrollos teóricos y artísticos como lo post feminista y post porno, aunque, es también ahí en donde muchos grupos feministas y de otras denominaciones como lo trans, mantienen su distancia frente a dicha teoría.

Las lesbianas autónomas decoloniales como Ochy Curiel y Yuderkys Espinosa, quienes defienden una lucha interseccional donde la raza y las comunidades negras juegan un papel político muy importante, se alejan radicalmente del uso queer o cuir debido a que el pueblo negro basa su lucha en una identidad histórica determinada, signada por la esclavitud, la opresión y la resistencia, por lo que el postulado de la desestabilización

\footnotetext{
5 De Lauretis comienza a utilizar desde entonces el término sujetos excéntricos y nos dice, "lesbiana no alude a una mujer individual, con una "preferencia sexual" particular o un sujeto social con una prioridad simplemente "política" sino un sujeto excéntrico, constituido en un proceso de lucha y de interpretación, de reescritura del propio yo, en relación a una nueva comprensión de la comunidad de la historia y la cultura... Es decir, un concepto teórico y al mismo tiempo, una postura eminentemente política, un posicionamiento frente al patriarcado, la heterosexualidad obligatoria, el racismo, el clasismo y el neoliberalismo."

6 "Y a la vez nos sitúa en una posición de extrañamiento, de una cierta exterioridad respecto de nuestra cultura nacional, en la cual somos/estamos exiliados." (David Córdoba, apúd. Rivas, 2011).
} 
de las identidades del queer implicaría, incluso, la disolución de parte importante de su actividad política, que también se aparta del feminismo blanco decolonial.

El feminismo comunitario surgido en Bolivia con Julieta Paredes es otro ejemplo de feminismos en la región que se apartan de los postulados queer ya que, según palabras de Paredes: ponerse bigotes no va a terminar con el patriarcado que oprime a todas y todos. Para ella un cambio en la forma de vestirse no determinará un cambio en las relaciones establecidas por el patriarcado. Por lo que considera a lo queer como una posición política estéril, además de ser colonial e individualista. ${ }^{7}$

En América Latina, queer ha chocado con las posturas decoloniales, ya que ha perdido su origen popular y ha sido adoptado por las élites bilingües, en estas tierras se convierte en lo que avala la normalización de la diferencia (que no disidencia) sexual, pierde en la frontera norte/sur su confrontación a los estudios gays y lesbianos como había sucedido en Estados Unidos e Inglaterra, para convertirse en una extensión de ellos tropicalizada. Con esto, no queremos decir que lo queer y la teoría queer sean herramientas políticas y teóricas erróneas, sino que es necesario ponderar sus postulados. Rivas (2011) nos dice que, el debate norteamericano del uso de la teoría queer y el sudamericano no puede desarrollarse de la misma manera, en tanto en el sur, sólo se retoman algunos autores como Beatriz Preciado quien no tiene fuerte repercusión en la academia norteamericana.

Las lesbianas autónomas latinoamericanas, aunque etiquetadas como pensadoras queer, toman su distancia respecto a dicho pensamiento y construyen desde su experiencia su teoría. Para pensar estas realidades y la construcción de una sociedad con relaciones más equitativas, la teoría queer, su diálogo y diferencia con el pensamiento feminista puede dotarnos de herramientas útiles. En un inicio, el movimiento queer, de disidentes sexuales y de género, atravesados por marcadores raciales y de clase, tenían mucho en común con buena parte de los sectores disidentes latinoamericanos. Incluso podría decirse que las locas, las fuertes, los homosexuales prostituidos de los barrios latinoamericanos y las lesbianas autónomas, también tienen como contraparte la sexualidad burguesa e ilustrada de la región, sin embargo, el debate en el continente se ha desarrollado de forma distinta, sobre todo en cuestiones de clase y raza que han sido filtradas por los usuarios de la teoría queer en América Latina.

\footnotetext{
7 Este debate tiene mucho que ver con la otra figura icónica del feminismo boliviano,
} María Galindo, quien presenta un feminismo más cercano al feminismo occidental. 
Las respuestas de las pensadoras latinoamericanas respecto a lo queer, por lo general son de rechazo, aunque hay algunas posturas en donde se rescatan aspectos útiles del término. Para Francesca Gargallo (2009), no existe un movimiento queer latinoamericano, aunque reconoce que algunos grupos se autodenominan así para tratar de romper pautas de género y sexualidad; éstos están desarticulados y no conforman un movimiento. También defiende que lo queer ha sido considerado por algunos grupos feministas como un intento de masculinizar el feminismo, esto es compartido por buena parte del feminismo latinoamericano que aseguran que es una forma de robar espacios feministas y femeninos a las mujeres. Sin embargo, no considera cerrada la posibilidad de reflexionar en torno a lo queer y piensa que,

...lo interesante de lo queer es el reto de la desnaturalización genérica a la política de las identidades fijas, así como a la reacción a la carrera institucionalizante y mercantil del movimiento gay. Lo más cercano en América Latina a esa experiencia ha sido la autonomía lésbica que, sin embargo, ha planteado críticas a la política queer porque ésta ha colaborado en desestructurar el sujeto estable del feminismo y nos ha vendido un nuevo sujeto supuestamente performatico... (Gargallo, 2009)

Más allá de la teoría queer, las lesbianas latinoamericanas, autónomas y decoloniales retan la crítica que se hace a los estudios sobre de la homosexualidad, preocupándose por pensar en mecanismos de liberación sexuales, de género, de clase y raza. Vivir la negritud, la pobreza, el lesbianismo y en muchos casos, la maternidad, las sitúan en una posición en la que las posibilidades de solidaridad con diferentes sectores oprimidos permiten pensar en espacios de lucha articulados a través de la diferencia. Voces decoloniales como la de Yuderkys Espinosa, considerada una pensadora queer latinoamericana, pero autoasumida como lesbiana utónoma. Una de sus críticas a la teoría queer es que considera "una reapropiación de la reapropiación", ya que además, invisibiliza las luchas de los pueblos afrodescendientes y los movimientos lesbianos que durante siglos han buscado construirse una identidad política por lo que, aunque no pugna por identidades cerradas, tampoco está a favor de hablar de la desestabilización de las mismas. Por su parte, Julieta Paredes (Paredes \& Guzmán, 2014) considera que el modificar su forma de aparecer genérico, es decir, performar-se con elementos masculinos si eres mujer, o con elementos identificados socialmente como femeninos al nacer varón, no se modifica la

8 Entrevista realizada a Yuderkys Espinosa en la Ciudad de México en diciembre de 2013. 
dominación patriarcal, pues los cuerpos, las subjetividades y las comunidades de las mujeres y los feminizados, se mantienen sujetos a los diversos dispositivos de exclusión del orden heteropatriarcal. Para ambas pensadoras, hay un factor que la teoría queer o al menos su uso latinoamericano ha dejado de lado: la construcción de comunidad. La construcción de comunidad dota también de historicidad a las luchas que articulan y que buscan llevar a cabo exitosamente proyectos de liberación.

Las pensadoras lesbianas se cuestionan sobre de la desestabilización de identidades propuesta por lo queer, ya que en las luchas políticas de disidencia sexual, las minorías lesbianas pobres, indias o negras han luchado por construirse una, sin renunciar a ninguna de sus pertenencias y con la conciencia de que la lucha de sus pueblos es también la suya. Ellas han encontrado como canales de expresión el ensayo y la poesía, como lo han hecho las feministas negras y las feministas chicanas del siglo pasado. Para ellas es la principal arma de decolonialidad al recuperar la memoria de aquellas que estuvieron antes, quienes desarrollaron su pensamiento en contextos de exclusión en territorios de los colonizadores. De tal forma que diáspora, interseccionalidad, colonialidad, modernidad, articulación y reciprocidad se tornan conceptos claves de resistencia y construcción de realidades distintas a las del modelo moderno liberal capitalista heteropatriarcal.

Vale la pena destacar que no se descartan las aportaciones de la teoría queer a las diversas construcciones críticas decoloniales, sin embargo, no se asume ciegamente su propuesta en un contexto distinto, el latinoamericano, en donde lo queer se asocia a las élites homosexuales europeizadas. La teoría queer por sí misma, no pasa por alto las problemáticas locales. Su uso no ha estado libre de actos de sofisticación académica de algunos grupos elitistas que se consideran post feministas. ${ }^{9}$ A pesar de esto, no es posible desechar elementos teóricos que pueden resultar útiles para analizar la exclusión y proyectar la emancipación. Más allá de un simple trasplante teórico o un rechazo ciego a lo extranjero, me parece que los conceptos de la teoría queer como performatividad o desestabilidad de identidades, nos ayudan a recordar que "Lo queer, como todo lo demás, no es nada necesaria y esencialmente, sino más bien lo que queramos y podamos hacer con ellas. Mantener una vigilia atenta a esta flexibilidad del término va a ser parte de nuestra tarea política." (Pérez, s/f)

9 Diversos grupos feministas se han pronunciado contra el uso del prefijo post, ya que esto implicaría que el sujeto del feminismo ha sido superado. Un ejemplo de dichos grupos, son las transfeministas españolas, que prefieren el sufijo trans en la idea de diálogo, intercambios y articulaciones entre feminismos, que incluyen a las feministas transexuales. 
El debate en torno al uso de lo queer está abierto. Sayak Valencia propone escribirlo como suena en español, cuir, para dar cuenta de las formas locales ya que para ella "No es una identidad, sino un proceso de autocrítica radical y de crítica a la sociedad y a sus categorías absolutas como lo masculino y lo femenino", por lo que el uso del término tiene que ver con una idea de proceso identitario que confronta lo establecido y lo que pretendemos ser. En un dossier llamado, ¿̇e puede hablar de queer en América latina? Editado por FLACso Ecuador se da cuenta del debate del uso que da a lo queer en donde podemos ver cómo las diversas posturas se mueven desde la defensa o ataque a la tropicalización del término hasta la aplicación de la teoría en textos literarios.

Es en esta última forma de uso de la teoría queer en donde nos encontramos en mayor desacuerdo, ya que aparece como una herramienta para analizar la disidencia sexual reflejada en la literatura latinoamericana de mediados del siglo xx, como si dicha producción se tratara de un pensamiento estático que no aporta sus propios elementos para pensar la realidad o como si no existieran desarrollos de conocimiento latinoamericanos para su análisis.

\section{LOCAS Y BRUJAS: LA LITERATURA DE DISIDENCIA SEXUAL LATINOAMERICANA}

Porque las lágrimas de las locas no tenían identificación, ni color, ni sabor, ni regaban ningún jardín de ilusiones. Las lágrimas de una loca huacha como ella nunca verían la luz, nunca serían mundo húmedos que recogieran pañuelos secantes de páginas literarias. Las lágrimas de las locas siempre parecían fingidas, lágrimas de utilería, llanto de payasos, lagrimas crespas, actuadas por la cosmética de la chiflada emoción.

Pedro Lemebel

El travesti, drapeado entre fantoches de irisable mondura: monda, monda: ronda, cercena y raspa: la mondura montada en cardenales, en fetiches: pescuezo de lamé, cuello de gata: botella atravesada: el irisado almácigo: hortelano: curva, cencerro y paja: la travesti echada en la ballesta, en los cojines crispa el puño aureolado de becerros: en ese vencimiento, o esa doblegación: de lo crispado: muelle, acrisolando en miasmas mañaneras la vehemencia del potro: acrisolando: la carroña del parque, los buracos de luz, lulú, luzbel: el crispo: la crispación del pinto: como esa mano homónima se cierne sobre el florero que florece, o flora: sobre lo que florea: el miché, candoroso, arrebolado de azahar, de azaleas, monta, como mondando, la prístina ondulación del agua: crueldad del firmamento, del fermento: atareado en molduras microscópicas, filamentosos mambos: tensas curvas 
En América Latina, encontramos en parte de la literatura del siglo xx una vasta reflexión acerca de los estándares heteropatriarcales instaurados por el orden moderno liberal capitalista. La disidencia sexual ha sido expresada y reflejada a partir de innumerables autores entre los que destacan Manuel Puig, Salvador Novo, Néstor Perlonguer, Pedro Lemebel, José Donoso, José Joaquín Blanco, Reinaldo Arenas, Severo Sarduy, Carlos Monsivais; también hay presencia, aunque menos visible, de escritoras de disidencia sexual quienes han caminado junto al feminismo en el continente, ${ }^{10}$ como Rosamaría Roeffiel, Ena Lucía Portela, Francesca Gargallo, Reina Roffé, Ochy Curiel, entre otras. ${ }^{11}$ Esta producción se dió por los mismos años en los que se desarrolló la teoría queer e incluso antes en diferentes géneros: poesía, la narrativa y el ensayo, que se han desarrollado con la proyección de la disidencia sexogenérica en escenarios populares a lo largo del continente. Sin embargo, los estudiosos del tema han insistido en pensar esta literatura a partir de las herramientas queer, por ejemplo, Gustavo Vargas en literofilia asegura:

En medio de una novela sumamente densa, Lezama se dedica en el octavo capítulo a crear una estética homosexual basada en una serie de escenas sexuales explícitas en medio de un excesivo neo-barroquismo que se con-

10 Entre las pioneras latinoamericanas, Olivera Córdova nos dice: "Es sorprendente, por ejemplo, la manera en que en Cuba los temas del feminismo y la sexualidad fueron tratados en las primeras décadas del siglo xx, a partir de los trabajos de Mariblanca Sabás Alomá reunidos en gran parte en su libro de 1930, Feminismo, cuestiones sociales y crítica literaria en donde reprodujo un artículo en contra del llamado garzonismo (1928); las reflexiones de Flora Días Parrado en defensa de dicha orientación sexual (incorporadas también en libro de Sabás), y la configuración de una personaje secundaria lesbiana en la novela de Ofelia Rodríguez Acosta de 1929, La vida manda, que escandalizó por su visión sobre la sexualidad y el amor libre. En Argentina, en 1845 se publicó la que para algunos autores es la primera novela del país independiente: La familia del comendador, de contenido antiesclavista en un ambiente matriarcal; en sentido similar la cubana Gertrudis Gómez de Avellaneda había publicado su novela Sab (1841), contra la esclavitud y el sometimiento femenino, y en 1842, Dos mujeres, una invectiva contra el matrimonio. En México, la española Concepción Gimeno abrió el panorama en 1885 con el Suplicio de una coqueta, y mucho más tarde Laura Méndez de Cuenca, en 1902, publicó por entregas El espejo de Amarilis, aunque el cuestionamiento al deber ser en torno a la sexualidad se vio claramente plasmado hasta 1938 en Andréida novela de Asunción Izquierdo...” (Olivera, 2014: 234).

11 Éstas autoras han sido analizadas en la tesis doctoral de Maria Elena Olivera (2014), quien hace un recuento muy importante de la literatura lésbica en América latina, a la vez que hace una refiguración de personajes lésbicos a disidentes sexogenéricas. Olivera comenzó esta labor en su libro Entre amoras Lesbianismo en la narrativa mexicana (Olivera Córdova, 2009). 
vertiría- posteriormente- en parte esencial del estilo queer en la literatura latinoamericana. Severo Sarduy, Reinaldo Arenas y Pedro de Jesús son algunos de los escritores que desarrollaron una sensibilidad neo-barroca en su producción literaria. (Vargas, 2013)

Es posible encontrar varias publicaciones en el mismo tenor, ${ }^{12} \sin$ embargo, sería preciso cuestionarnos acerca de la pertinencia del uso de queer, cuando se habla de neo barroco. Ya que incluso el mismo Lezama Lima se negaba a seguir pautas estéticas europeas, buscaba el ser americano a través del neobarroco, ${ }^{13}$ buscaba la creación de estéticas propias, complejas, no el simple seguimiento a una línea de pensamiento dada en otro contexto. El barroco y el neo barroco han sido una constante en la literatura latinoamericana y aunque vale la pena dejar claro que no toda la literatura de disidencia sexual es neo barroca ni toda producción neobarroca toca temas de disidencia sexogenérica. La complejidad del mismo han servido de herramientas para los pensadores de la disidencia sexual que han encontrado en la dinámica de los excesos un canal de expresión propicio. En este sentido, encontramos a Néstor Perlongher quien hace una adaptación rioplatense del neo barroco y lo llama neo barroso en referencia al barro del Río de la Plata, barro que trae consigo cadáveres de los desaparecidos durante la dictadura argentina. El neo barroso no es jamás neutro, es político, es una forma de concretar una disidencia sexo genérica, de clase, antineoliberal:

Perlongher se opuso explícitamente a esta imposición conceptual y política desde EEUU y desarrolló en su poesía neobarrosa, un modelo de subjetividad homosexual que interrumpe los flujos deseosos (los cuales se acomodan con la ideología económica neoliberal). Esto lo llevó a cabo, primero a partir de una insistencia temática y formal en las muertes y cadáveres que asentaron este modelo libidinoso en el Río de la Plata y que siguen vagando en sus aguas barrosas; $y$, segundo, a partir de la insistencia en prácticas homosexuales que no se conforman con la proyección de una

12 Por ejemplo, César Cañedo en Cuadrivio habla de Salvador Novo y su vida y obra queer (Cañedo, 2015) y el número 4 de Lectures du genre llamado "Lecturas queer desde el cono sur" dedica toda su producción a encajar varias obras latinoamericanas de disidencia sexual en el cajón queer.

13 Lezama Lima buscaba construir una obra compleja a partir de elementos latinoamericanos que no fuese necesariamente una copia ni una adaptación del barroco europeo. Junto con Severo de Sarduy y Virgilio Piñeira es considerado parte del neo barroco cubano. (Tavares, 2015) 
homosexualidad integrada al mercado neoliberal. El "barro" rioplatense (contaminado con los vestigios de la desaparición y ejecución de miles de opositores políticos) literalmente "enchastra" los logros de un modelo que se quiere limpio, liso y llano como el infinito fluir de la metonimia del deseo. (Gundermann, 2003)

Para Perlongher, el exceso "sucio" del neobarroso es también una forma de ser "furiosamente antioccidental", ${ }^{14}$ por lo que las lecturas queer que de su obra se hacen deberían apuntar hacia un análisis de su obra en clave barroca antes que hacerlo desde una herramienta teórica hegemónica; con la obra de Perlongher como forma de resistencia ante la modernidad capitalista desde la disidencia sexogenérica, se podría hacer uso del neo baroso como herramienta de análisis frente a una realidad opresiva no sólo contra la disidencia sexogenérica sino opresiva frente a cualquier signo de disidencia política. De tal forma que el exceso neo barroso se expresa en formas estéticas pero es a la vez una forma de denuncia contra el uso ciego de teorías occidentales e ironiza acerca de la normalidad homogenérica.

Néstor Perlongher es un ejemplo de la forma en que en la literatura latinoamericana a través de la narrativa, el ensayo y la poesía, devela la doble moral de sociedades machistas que han aceptado en la convivencia diaria a distintas formas de disidencia sexual y de género sin renunciar a distintas formas de acoso, violencia y escarnio. Se trata de dispositivos de disciplinamiento de género y sexualidad que van a encontrar otras formas de resistencia a través de diversas estrategias, una de ellas es la actuación de modelos tipo como la loca de barrio que encontraremos en obras de otros autores latinoamericanos: Néstor Perlongher y Pedro Lemebel.

La loca de barrio es una figura de travestismo popular, es decir, el disidente sexual negado por los sectores homosexuales masculinos elitistas que buscan integrarse al orden existente. Es la loca de barrio la que reta los roles cerrados de género y sexualidad, la que desestabiliza las pautas cerradas de identidad. Esta figura, retrata una disidencia sexual atravesada por otros factores de marginación además del género y la sexualidad; en ellas se refleja la exclusión por clase y en muchas ocasiones, por raza. La interseccionalidad de la exclusión reflejada en la literatura latinoamericana a través de la loca de barrio, surge por los mismos años (algunas

\footnotetext{
14 "Es el plano de la forma que el barroco, ahora el neobarroco atacan... Es un ente furiosamente antioccidental, listo a aliarse o entrar en mixturas "bastardas" con culturas no occidentales", (Perlongher, apúd. Tavares, 2015).
} 
novelas incluso algunos años antes) que la primera teoría queer. Basta echar un vistazo a El beso de la mujer araña, Lugar sin límites, Tengo miedo torero de Manuel Puig, José Donoso y Pedro Lemebel respectivamente, para comprender que desde los lugares no privilegiados de producción de conocimiento se construía una postura crítica y política de la homosexualidad masculina y sus diversas prácticas. Puig y Donoso caracterizan a sus personajes principales como disidentes sexogenéricos cuyas prácticas políticas enfrentan a un régimen dictatorial. Esto es importante, ya que aunque la disidencia sexual global tiene como gran punto simbólico Stonewall, y como teoría hegemónica la teoría queer, la reflexión y la búsqueda de liberación de prejuicios ante las sexualidades diversas ya se desarrollaba y, en la práctica, ya aparecía en los barrios latinoamericanos. Resulta sorprendente que los estudiosos de las novelas y cuentos de disidencia sexual en América Latina sean abordados desde la teoría queer, cuando dentro de la diégesis de dichas obras se encuentra de inicio inscrita, una fuerte crítica a las condiciones de la homosexualidad marginal, a las jerarquizaciones dentro de la homosexualidad masculina, es decir, a la aún mayor marginada condición de los prostitutos y los travestis que a su vez, implica la superioridad social de los homosexuales de clase alta, a quienes también retratan en toda su excentricidad, por ejemplo en El vampiro de la colonia Roma de Luis Zapata.

El disidente sexual o de género en los barrios, nunca ha sido ajeno a la cotidianidad, como tampoco ha sido ajena la marginación en la que se han encontrado en sociedades profundamente machistas en las que, incluso en tiempo de apertura a la diferencia, existen parámetros para normalizar la homosexualidad másculina o femenina a partir de dispositivos generonormativos, para asir a ciertas pautas de normalidad a las y los distintos. Este proceso fue mucho más violento en tiempos de dictadura en América latina. Es en este cruce entre la convivencia popular y el discurso machista de discriminación, donde la homosexualidad masculina y femenina han llevado a cabo reflexiones críticas ante el orden existente en América Latina y parece que muchos de los ejemplos en la región vienen a través del arte. Las letras latinoamericanas nos resultan sumamente importantes en esta práctica crítica/resistencia ya que en ellas se refiere la complejidad de las construcciones sociales: no se conforman con hablar de la marginación por su diferencia sexual, su disidencia de género; también se retratan las intersecciones de esa marginalidad con los problemas de clase, el maricón 
pobre; de raza, el travesti mapuche o el costurero negro. Critican e ironizan acerca de las construcciones de masculinidades y feminidades, de los roles cerrados, e incluso o sobre todo, de los prejuicios sobre el gay de clóset y sobre la loca.

La literatura ha funcionado como reflejo de las sociedades latinoamericanas, a la vez que realiza agudas críticas a la doble moral convivencia/ discriminación. Para Donoso, la Manuela resulta un personaje entrañable, amigable, solidaria, creyente (nunca falta a misa los domingos, salvo el domingo en que tiene miedo del hombre que la busca porque la considera suya). Lo mismo se puede decir de los personajes de Lemebel: travestis sexoservidoras que se cuidan entre si al contraer el sidA; retratos de la plaga que se adueña del cuerpo de la Madonna mapuche o de la negra Loba Lamar quien era "una lágrima de lamé negro, un rescoldo pisoteado del África travesti..." (Lemebel, 2000); locas cómplices de estudiantes universitarios que resisten a la dictadura de Pinochet. Se muestran diversos rostros de un travestismo popular, cruzado no sólo por su disidencia de género y sexual, sino también por sus problemas de raza y clase: su extrema pobreza, su carencia de estabilidad laboral, para ellas es imposible siquiera pensar en prestaciones sociales. Disidentes sexuales destinados a la muerte pobre, en muchas ocasiones solitaria. La disidencia sexual popular latinoamericana va acompañada de la marca de la loca, la marca del travestismo, del exotismo, de la exageración barroca en el vestir, el peinar, el hablar que las condena a una vida -y muerte- míseras.

Por supuesto, es imposible asegurar que toda disidencia sexual o que toda preferencia sexual distinta a la heterosexual vaya de la mano de las prácticas de la loca, sin embargo, dichas prácticas son las que se alejan más de los procesos de normalización de las prácticas de diversidad sexual desarrolladas por el orden moderno/liberal capitalista: en ellas no se solicita que se establezca el matrimonio entre personas del mismo sexo, ni una familia con padres del mismo sexo, porque encajar en las estructuras ya impuestas a las heterosexualidades no es su prioridad. En muchas ocasiones es posible leer cómo el travestido es el que se encuentra en menor estima entre los homosexuales, incluso, por debajo de los prostitutos identificados genéricamente con lo masculino. Es por esto que consideramos a la loca como una posición de crítica y reflexión en torno al orden social existente, que no sólo se ha reflejado en la novela. 
Es así que la literatura latinoamericana de disidencia sexual da un paso importante en el reflejo de lo que sucede: discurso discriminatorio en lo público y convivencia y aceptación en la comunidad cercana. La loca tuvo a lo largo del siglo xx la aceptación que tuvieron los personajes literarios latinoamericanos del mismo sexo y sus motivos, aunque como dice Carlos Monsivais:

A la tradición de Lemebel pertenecen, entre otros muchos, el argentino Néstor Perlongher, el mexicano Joaquín Hurtado, el puertorriqueño Manuel Ramos Otero, el cubano Reynaldo Arenas y, un tanto más a distancia, el cubano Severo Sarduy y el argentino Manuel Puig. (El común denominador: el sida). Es una literatura de la indignación moral (Perlongher, Ramos Otero, Arenas, Hurtado), de la experimentación radical (Sarduy), de la incorporación festiva y victoriosa de la sensibilidad proscrita (Puig). En todos ellos lo gay no es la identidad artística sino la actitud contigua que afirma una tendencia cultural y un movimiento de conciencia. No hay literatura gay, sino la sensibilidad ignorada que ha de persistir mientras continúe la homofobia, y mientras no se acepte que, en materia de literatura, la excelencia puede corresponder a temas varios. (Monsivais, 2000)

Nos mantenemos en esta idea de Monsivais: en la literatura latinoamericana de disidencia sexogenérica del siglo $\mathrm{xx}$, existe una tendencia cultural y un movimiento de conciencia, no se trata simplemente de la construcción de una identidad artística. Sin embargo, se trata de un movimiento de conciencia que implica un cuestionamiento a la normalización de las diversas formas de opresión desde una obra original frente a las formas hegemónicas de pensamiento occidentales.

Durante los setenta y ochenta se escribieron novelas importantes que tenían que ver con disidencia sexual, la primera y generalmente mencionada es El vampiro de la colonia Roma de Luis Zapata, que retrata la historia de un joven prostituto en la Ciudad de México, aunque a la par de ella surgen muchas otras como Las púberes canéforas de José Joaquín Blanco, aunque hay algunas pocas anteriores como El diario de José Toledo de 1964 de José Barbachano. Vale la pena decir que la literatura de disidencia sexual estuvo sometida a decisiones y mercados editoriales. De tal forma que aunque hubiese habido obras con temáticas distintas a las heteronormativas habría sido muy complicado que fuesen impresas y distribuidas a una cantidad de lectores mayor. María Elena Olivera nos señala:

En Latinoamérica, en cambio, la literatura homosexual es un fenómeno emergente que inició de manera heterogénea y pausada después de la segunda mitad del siglo $\mathrm{xx}$, y que no ha contado, salvo tal vez de manera 
muy reciente y sólo en algunas regiones, con los respaldos académico y editorial. Asimismo, es nuevo el interés de reunir textos que habían estado dispersos y semi ocultos en revistas o libros de literatura general, de promover y compilar escritos de nueva creación y de integrar los análisis de estos materiales a los estudios e investigaciones universitarias; de hecho, antes que en algún país latinoamericano fue en la propia academia estadounidense donde surgió el interés por incorporar la literatura homosexual de Latinoamérica en la investigación y enseñanza de algunas universidades. (Olivera Córdova, 2014, pág. 21)

De tal forma que nos encontramos ante literatura cuasi marginal, debido a que los temas que le dan sustento han sido censurados, aunque en algunos casos como los de Donoso y Puig sus obras de disidencia sexual se han entremezclado con otras obras con temática distinta.

Más complicado es encontrar narrativa lesbiana, aunque destaca Amora de Rosamaría Roffiel y los poemas de Nancy Cárdenas en México, mientras en Argentina Reina Roffe con su segunda novela Monte de Venus de 1976 fue sacada de circulación. Como bien apunta Olivera (2014), las escritoras latinoamericanas que han tratado temas de disidencia sexogenérica han padecido una especie de "pánico" de ser encasilladas como lesbianas o escritoras de pornografía, ya que según la autora, se sufre una triple discriminación al ser mujeres, lesbianas y latinoamericanas. Lo que implica que el locus de enunciación es relevante para la construcción de fronteras de exclusión. Esta es una de las razones por las que el sentido de queer no puede aplicarse en contextos latinoamericanos tal cual, aunque se insiste que algunas de sus herramientas pueden servir para pensar las obras de disidencia sexual, sin embargo, no alcanza a dar cuenta de las obras en contextos populares heteropatriarcales latinoamericanos.

La lista de literatura latinoamericana de disidencia sexual después de los años ochenta es larguísima y este espacio no es el adecuado para hablar de toda la obra, ya que, además, no se busca solo señalar las obras de homoerotismo. Hemos puesto los ojos sobre los escritores locas y las escritoras brujas, condenadas por su relación erótico amorosa con otras iguales a ellas.

La loca resulta una figura interesante porque se coloca justo como lo marginal en el mundo no artístico (del performance o los grandes poetas) ni normalizado de la disidencia sexual. Se trata de la figura en donde se cruzan las exclusiones de sexualidad, género, raza y pobreza. Se construye esa figura en la literatura, más tarde en los estudios sociales al pensar lo 
cuir latinoamericano. Sin embargo, lo importante de esa figura es que vive, que resiste, que encarna más de lo que la teoría queer retomada por la teoría y práctica de élite homosexual latinoamericana ha dicho. La loca tiene un origen parecido a lo queer original, sin embargo, no es lo mismo y se parece cada vez menos a las reapropiaciones latinoamericanas del siglo XxI.

En un artículo ecuatoriano titulado "Locas y fuertes" se alude a una forma de ser cuir, a una forma de ser un travestismo popular, relegado por las élites gays que enarbolan lo queer y lo LGTTB, que defienden su derecho a pertenecer al orden creado desde la modernidad heteropatriarcal capitalista. Se trata de las trabajadoras sexuales pobres, de las de oficios de maquila, de las que viven abusadas, violentados, que bien retrata Lemebel en su Loco Afán desde Chile o Mayra Santos-Febre desde El Caribe. De tal forma que encontramos en la loca, al travestismo popular que enarbolaban los primeros queer ingleses, aunque el término se pervirtió en Latinoamérica en donde el factor de clase y de raza se despega de las marginaciones de sexualidad y género en pos de una ciudadanización de consumo.

De tal suerte que las lágrimas de las locas han sido parte de la cotidianidad de los barrios pobres en América Latina. Lágrimas, maquillaje, actitud, han sido parte de la vida de las grandes ciudades, de sus márgenes, en donde las locas han encontrado espacios como costureras, estilistas, cocineras. Se les ha construido un lugar en los oficios considerados femeninos, se mantiene su decisión. Las locas, las fuertes, son también diseñadoras de espacios que la literatura ha retratado en novelas como Tengo miedo, torero de Pedro Lemebel o El lugar sin límites de José Donoso; espacios que los analistas literarios, en el mejor de los casos, anudan a la tradición barroca a través de Severo Sarduy y que para nosotras y nosotros será la pauta para pensar en las reflexiones acerca de la disidencia sexual desde América Latina, en donde a la par de la producción de narrativa, se desarrolló el ensayo, que también enuncia claramente la intersección de dispositivos de opresión: clase, sexualidad, género y raza. Por lo que las locas literarias no se quedan en las crónicas, las novelas o cuentos. La fuerte como figura estrafalaria, disruptiva, degenerada, se encuentra entre muchos ensayistas disidentes que encuentran las semillas para la construcción de un orden distinto, sin las jerarquías que conocemos, lejos de la homosexualidad normalizada, alejados del canon sexogenérico y conscientes de otros dispositivos que funcionan de forma potente para excluir, como la clase y la raza. Los escritores y las escritoras 
latinoamericanos, saben que no es lo mismo ser un homosexual adinerado, blanco, occidentalizado, que un disidente sexogenérico de barrio, negro, india, que no encuentra lugar ni como hombre ni como mujer, aunque es oprimido y explotado al no cumplir el canon, por tratarse de un ser humano feminizado, por ser un ser humano, varón o hembra, que deviene mujer, como lo explica Perlongher (1993).

En el rubro de ensayo destacan Carlos Monsivais y José Joaquín Blanco en México, así como Néstor Perlongher en Argentina y Pedro Lemebel en Chile. En el brillante ensayo de Blanco de 1979, Ojos que da pánico soñar, queda claramente señalada la diferencia de clase entre la marginada homosexualidad, sobre todo en las ciudades; mientras tanto, avizora un escenario de normalización que asegure espacio de confort a aquellos homosexuales que puedan pagarlos, lo que llevará a los disidentes sexuales y de género de su tiempo (finales de los setenta) a renunciar a los privilegios del rebelde, a renunciar a su diferencia política, al afán crítico del perseguido, a la valentía para cuestionar el orden del distinto que asume su diferencia, a la indiferencia por instituciones como la familia o la intención de acumular. De la misma forma, dice que los homosexuales pobres, los prostitutos, no tendrán mayor cambio en sus vidas, seguirán explotados, extorsionados, perseguidos:

No me atrevo a hablar de la homosexualidad en la miseria. Somos tan poca cosa (homosexuales de clase media) frente a ella: esos homosexuales de barrio, jodidos por el desempleo, el subsalario, la desnutrición, la insalubridad, la brutal expoliación en que viven todos los que no pueden comprar garantía civil alguna; y que además son blanco del rencor de su propia clase, que en ellos desfoga las agresiones que no pueden dirigir contra los verdaderos culpables de la miseria: esas locas preciosísimas, que contra todo y sobre todo, resistiendo un infierno totalizante que ni siquiera imaginamos, son como son valientemente, con una dignidad, una fuerza y unas ganas de vivir, de las que yo y acaso también el lector carecemos. Refulgentes ojos que da pánico soñar, porque junto a ellos los nuestros parecerán ciegos. (Blanco, 1979)

La solidaridad entre la homosexualidad masculina, estará dividida por la clase, por el espacio que se ocupa, los privilegios pesan más que las exclusiones comunes, "ninguna sexualidad es ajena, sino directamente condicionada por el nivel de vida de las personas y su ubicación en las clases sociales de determinado momento." (Blanco, 1979: 187) Treinta y cinco años después, sus conjeturas no resultan ajenas a las realidades de 
las disidencias sexuales y de género, se trata de críticas que aún en estos días realizan las lesbianas feministas autónomas quienes también a través del ensayo han hecho escuchar su voz disidente contra la norma heteropatriarcal, Ochy Curiel y Yuderkys Espinosa hacen una crítica aguda al orden que pretende desexualizar las relaciones de opresión.

Para Blanco, la homosexualidad no tiene esencia sino historia y es en ella en donde podemos rastrear los espacios que se abren y los que se mantienen cerrados a los disidentes sexuales, en donde, el ejemplo más burdo es el capitalismo:

Los gobiernos verticales, aún los socialistas (la URss, Cuba) han buscado exterminar la diferencia viva de los homosexuales, con recursos que no excluyen los campos de concentración. Las "democracias" capitalistas han seguido una política no menos criminal pero más sofisticada: para domesticar a una población, no se trata ahora de imponerle normas sobre con quien se hace el amor sino de cómo hacerlo: una sexualidad hedonista de consumo, prefabricada y sobrestimulada con recursos tecnológicos, en la que el sexo se banaliza y cosifica, y ya no importa ninguna transgresión sexual porque el sexo, como todo el cuerpo, ha dejado ahí de tener importancia. (Blanco, 1979: 186)

La diferencia política de la homosexualidad será finalmente ahogada y banalizada en un sistema de consumo, por un lado, mientras los disidentes sexuales pobres se mantendrán excluidos. Por lo que para Blanco las formas de resistencia se encontrarán entre quienes "insisten en el sexo y en el cuerpo como formas radicales de vida, fuentes de transformación y creatividad, que irradian su energía a todos los actos cotidianos, y los vuelven más generosos, inteligentes y dignos de ser vividos." (Blanco, 1979: 184) No sólo desde la homosexualidad, sino desde las diferentes formas de amar, por lo que la solidaridad será la actitud determinante para conformar la rebeldía ante los embates de la idea de estatus por consumo.

Por su parte, Perlongher estudió las condiciones de vida de los prostitutos brasileños, los taxyboys, los chichifos. Hablará de su pobreza y de su persecución por parte de las autoridades policiales (de quienes hará continuo escarnio) y de las dictaduras militares, para él, la homosexualidad no debe ser abordada desde el punto de vista del goce sino del terror. ¿Cómo podría existir goce en la persecución y en la muerte? Su continuo diálogo crítico con la obra de Deleuze y Guattari, da cuenta de una lucidez intelectual a la que han encasillado como queer latinoamericano, cuando como bien apunta Marisanty (2008), la teoría queer tiene como uno de 
sus referentes más importantes el post estructuralismo de Derrida. Por lo que existe una "genealogía diferenciada" entre el queer norteamericano y el "queer" perlongheriano y de Lemebel. Me parece que es un texto que vale la pena revisar, ya que en él se afirma que aunque no se trata de pelear primicias, desde América latina el pensamiento de disidencia sexual ya se había cuestionado acerca de las luchas políticas desde la construcción de identidades:

A comienzo de los ochenta (y que quede claro que no se trata de competir por la primicia y la exclusividad de ciertos planteos), Perlongher se apropia del pensamiento de Deleuze y Guattari y realiza a partir de ellos un cuestionamiento netamente postestructural a la política de la representación y de la configuración de identidades que inmovilizan a los sujetos que interpelan. Así como Butler, en el primer capítulo de El género en disputa (Butler, 2001), ponía en evidencia la crisis representacional del movimiento feminista y cuestionaba el concepto de identidad, el poeta argentino, unos años antes, hacía una observación similar acerca de las estrategias identitarias de los movimientos minoritarios que tienden a formar "guetos" y propiciaba la insubordinación de las subjetividades disidentes, como forma de resistencia al control estatal y al "adecentamiento" asimilacionista de los propios grupos minoritarios. (Marisanty, 2008)

Esto es una muestra del absurdo de encasillar al pensamiento de disidencia sexual latinoamericano en el vocablo hegemónico occidental queer. Hablar de queer desde Perlongher, Lemebel o alguna de las primeras novelas de disidencia latinoamericana de mediados del siglo xx retrata una intención de forzar una teoría hegemónica a un pensamiento autónomo de disidencia latinoamericana.

Por otro lado, las mujeres, las lesbianas, las nuevas brujas, se han enfrentado a múltiples formas de discriminación. En muchas ocasiones, la lesbofobia es más cruel que la homofobia; la apertura de espacios desde el orden moderno liberal capitalista es hacia la homosexualidad masculina en un esquema claramente patriarcal pero también colonial y racista. Las mujeres lesbianas que encajan en los parámetros de éxito del modelo actual son mujeres blancas, norteamericanas o europeas, por lo que los esfuerzos de las disidentes sexogenéricas latinoamericanas tienen mucho que aportar en estrategias de resistencia, lucha y más importante, construcción de comunidad. Ellas no dejan de lado la lucha por su pueblo, hombro a hombro con sus comunidades negras, indias, urbanas de clase media y baja. 
Es a partir de estos apuntes, en un contexto de locas y brujas, de tortilleras y fuertes, que podrían construirse teorías de disidencia sexual, alimentadas con las problemáticas de la región, menos planas que las importadas, que se sustentan interseccionalmente, que dan cuenta además de un análisis de nuestras realidades, de estrategias para sobrevivir y construir comunidades con relaciones distintas entre las diferencias.

\section{BIBLIOGRAFÍA}

BLANCO, J. J. (1979); “Ojos que da pánico soñar”, en J. J. Blanco, Función de media noche. México: ERA.

CAÑEDO, C. (abril de 2015); Cuadrivio, en "Salvador Novo: queer frente al canon". http://cuadrivio.net/dossier/salvador-novo-queer-frente-al-canon/

GARGAlLO, F. ( 2009); A propósito de lo queer en América latina. ¿Existe, se expresa de algún modo el pensamiento queer en América latina?, Revista Blanco Móvil, pp. 94-98.

GUNDERMANN, C. (2003); Perlongher (y) el neobarroso, Revista de crítica literaria latinoamericana, 58, pp. 131-156.

LEMEBEL, P. (2000); Loco afán: crónicas de un sidario, España: Anagrama.

MARISANTY, J. J. (2008); ¿Una teoría queer latinoamericana ?: Postestructuralismo y políticas de la identidad en Lemebel, Lectures du genre núm. 4: Lecturas queer desde el Cono Sur.

MOGROVEJO, N. (mayo de 2010); ¿Es lo queer un concepto político? www. lifeperu.org/files/pdf/cendoc/lecturas\%20concepto\%politica.pdf (15 de abril de 2014).

MONSIVAIS, C. (2000); "Pedro Lemebel: del barroco desclosetado", Revista de la Universidad de México. www.revistadelauniversidad.unam.mx/4207/ pdfs/5-12.pdf.

OLIVERA CÓRDOVA, M. E. (2009); Entre amoras Lesbianismo en la narrativa, México: CEIICH-UNAM.

(2014); Narrativa Sáfica latinoamericana: una lectura tortillera. México: tesis para obtener el grado de Doctora en Humanidades, UAM-I.

PAREDES, J., y Guzmán, A. (2014); El tejido de la rebeldía ¿Qué es el feminismo comunitario? La Paz: Comunidad creando mujeres creando.

PÉREZ, M. (s.f.); Homonorma y heteroqueer, o no todo lo que brilla es oro y visceversa, en Las disidentes. http://lasdisidentes.com/2013/11/24/homonorma-y-heteroqueer-o-no-todo-lo-que-brilla-es-oro-y-viceversa1/

PERLONGHER, N. (1993); Prosa plebeya, Buenos Aires: Colihue. 
RIVAS SAN MARTÍN, F. (2011); "Digan queer con la lengua afuera: sobre las confusiones del debate latinoamericano", en Por un feminismo sin mujeres, Santiago de Chile: Territorios Sexuales editores.

TAVARES, P. (2015); Cinco cuentos entre el barroco y la modernidad. El neobarroco perlonghiano, Revista UNIABEU Belfor Roxo, 8, 18, pp. 364-378.

TELLEZ-PON, S. (28 de abril de 2014); Luvina. http://luvina.com.mx/foros/ index.php?option=com_content\&task=view\&id=696\&Itemid=49

VARGAS, G. (junio de 2013); Literofilia, en "La pasión invisible: Aproximaciones a la literatura lésbico-gay latinoamericana”. http://literofilia.com/?p=13052 